\title{
Estimasi Persentase Karbon Organik pada Tanah di Hutan Mangrove Alami, Perancak, Bali
}

\author{
I Gusti Agung Ayu Mirah Indraiswari ${ }^{a}$, I Dewa Nyoman Nurweda Putra ${ }^{a}$ \\ ${ }^{a}$ Program Studi Ilmu Kelautan, Fakultas Kelautan dan Perikanan, Universitas Udayana, Kampus UNUD Bukit Jimbaran, Bali 80361, Indonesia
}

\section{ARTICLE INFO}

\section{Article history:}

Received May $15^{\text {th }} 2018$

Received in revised form July $17^{\text {th }} 2018$

Accepted August $14^{\text {th }} 2018$

Available online September $4^{\text {th }} 2018$

\section{Keywords:}

Percentage of organic carbon

Belowground

Natural Mangrove forest

Vertical variation

\section{ABSTRACT}

\begin{abstract}
Mangrove is one coastal ecosystems that play a role in taking and storing a number of carbon known as Coastal Blue Carbon. Soil storage (below-ground) in mangrove forests has a potential of $50 \%$ to $90 \%$ more than the total carbon stock of coastal ecosystem. This study was conducted at 3 plots in Perancak Mangrove Forest, Jembrana, Bali with the aim of estimating the percentage of organic carbon and to find out the percentage of vertical variation of organic carbon in the soil. Sampling time was conducted in June 2015. The data required to calculate the percentage of organic carbon in the soil is the depth of soil samples, depth and sub-sample intervals, and bulk density. The results found that the percentage of organic carbon in the soil in Perancak natural mangrove was $50.235 \%$ or $185.968 \mathrm{Mg} / \mathrm{ha}$. Vertically the percentage of organic carbon in soils in Perancak natural mangrove forests was varies. The lowest value of bulk density depth of $0-15 \mathrm{~cm}$ was $0.07 \mathrm{~g} / \mathrm{cm} 3$ plot 1 and the highest was $0.20 \mathrm{~g} / \mathrm{cm} 3 \mathrm{in}>100$ $\mathrm{cm}$ depth plot 3. The lowest value of the percentage of organic in the depth $>100 \mathrm{~cm}$ was $47.899 \%$ plot 2 and the highest was $51.821 \%$ in the depth of $50-100 \mathrm{~cm}$ at plot 1 . The lowest value of soil $\mathrm{C}$ was $17.361 \mathrm{Mg} / \mathrm{ha}$ in the depth of $0-15 \mathrm{~cm}$ and the highest was $62.962 \mathrm{Mg} / \mathrm{ha}$ in the depth of $50-100 \mathrm{~cm}$ plot 1.
\end{abstract}

\section{Pendahuluan}

Mangrove, rawa dan lamun merupakan ekosistem pesisir yang dapat memberikan berbagai fungsi dan manfaat, salah satunya dalam upaya mitigasi dan adaptasi perubahan iklim. Ekosistem ini dapat mengambil dan menyimpan sejumlah karbon yang dikenal dengan istilah Coastal Blue Carbon dari atmosfer dan laut (Duarte et al., 2005). Blue Carbon merupakan karbon yang disimpan dalam mangrove, rawa, dan padang lamun di dalam sedimen, biomassa di atas permukaan tanah yang hidup (daun, cabang, batang), biomassa di bawah permukaan tanah (akar), dan biomassa tak hidup (sampah maupun kayu yang mati) (Mcleod et al., 2011).

Salah satu kawasan mangrove yang tersebar di Bali yaitu di kawasan Estuari Perancak. Sekitar tahun 1980, sisa luasan kawasan hutan mangrove setelah mengalami konversi areal pertambakan sebesar 177,09 ha (Balai Riset dan Observasi Kelauatan, 2009). Menurut Balai Riset dan Observasi Kelautan (2009) lahan mangrove di Perancak sebesar 178,6 ha dan terdapat lebih dari 390 ha lahan tambak. Donato et al. (2012) menyatakan salah satu hutan terkaya penyimpanan karbon di kawasan tropis adalah mangrove. Sehingga mangrove berpotensi dikaji dalam kaitannya dengan peranannya sebagai penyimpan karbon (blue carbon). Penyimpanan karbon mangrove di bagian bawah permukaan tanah merupakan penyimpanan terbesar dalam vegetasi ekosistem pesisir dan pengukurannya dapat menentukan perubahan jangka panjang penyimpanan karbon berkaitan dengan tekanan, perubahan iklim, dan perubahan lahan. Penyimpanan karbon di bawah permukaan tanah (below-ground) di hutan mangrove memiliki potensi $50 \%$ sampai $90 \%$ lebih dari total seluruh stok karbon ekosistem pesisir (Howard et al., 2014).

Distribusi vertikal di tanah merupakan salah satu aspek dari simpanan karbon organik yang masih kurang dipahami. Untuk memperkirakan penyimpanan SOC (Soil Organic Carbon) global pada kedalaman sangat berhubungan dengan distribusi vertikal SOC (Jobbagy and Jackson, 2000). Simpanan kandungan karbonorganik tinggi pada tanah sebesar $49-98 \%$ dalam hutan mangrove berada pada kedalaman antara 0,5 hingga lebih dari 3 $\mathrm{m}$ (Donato et al., 2012). Lunstrum (2014) menemukan konsentrasi C-organik pada tanah hutan mangrove alami pada kedalaman 1 meter berkisar 0,62\%-2,43\%. Ati, dkk. (2014) juga menemukan simpanan karbon mangrove di Teluk Miskam, Tanjung Lesung berkisar antara $0,78-9,51 \%$ atau 4,43-27,92 $\mathrm{Mg} / \mathrm{ha}$.

Mengingat kajian penelitian ini penting untuk dilakukan sehingga studi ini bertujuan untuk mengestimasi persentase karbon organik dan mengetahui variasi secara vertikal persentase karbon organik pada tanah di hutan mangrove alami Perancak. Hasil penelitian ini diharapkan dapat menjadi informasi dasar pengetahuan mengenai potensi penyerapan karbon organik dan 
variasi secara vertikal persentase karbon organik pada tanah di hutan mangrove alami Perancak.

\section{Metode Penelitian}

\subsection{Waktu dan Lokasi Penelitian}

Sampel sedimen diambil pada stasiun lapangan Balai Penelitian dan Observasi Laut (Gambar 1. Lokasi Penelitian) yang merupakan hutan mangrove alami pada tiga plot, yaitu F1 (Natural Forest), F2 (Natural Forest II), dan F3 (Natural Forest III).

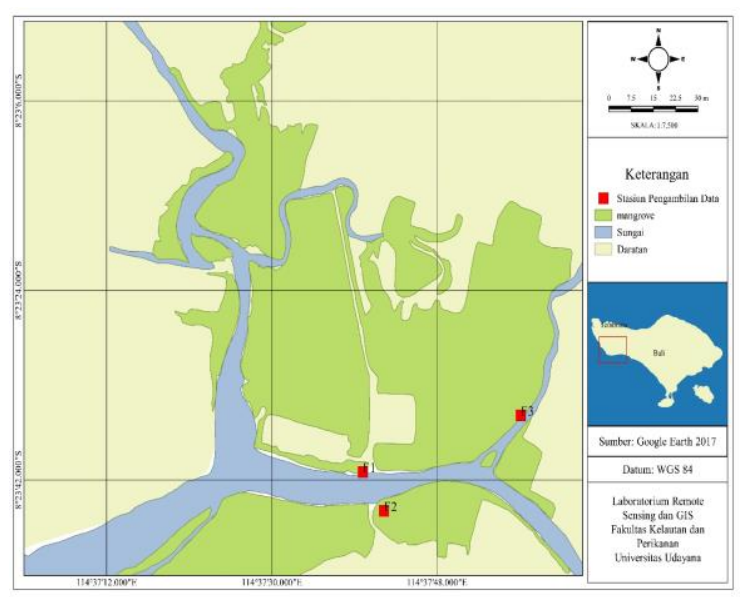

Gambar 1. Lokasi Penelitian

\subsection{Metode Pengumpulan Data}

Persentase karbon organik dalam tanah di analisa dengan pengambilan sampel tanah dengan mengacu pada Buku Coastal Blue Carbon (Howard et al., 2014), yaitu kedalaman sampel tanah, kedalaman dan interval sub-sampel, dan bulk density (kerapatan limbak).

\subsubsection{Prosedur Pengambilan Sampel}

Untuk pengambilan sampel, tahapan kerja yang dilakukan sebagai berikut, jika terdapat sampah organik dan daun hidup dari permukaan tanah dibersihkan sebelum pengambilan sampel dilakukan dengan menggunakan opened-face Auger. Langkah kedua, perangkat opened-faced Auger dimasukkan saat proses coring ke dalam tanah secara vertikal sampai kedalaman mencapai pangkal corer. Pengambilan sampel dipindah ke lokasi lain jika coring tidak dapat menembus kedalaman penuh (sampai pangkal corer). Corer diputar untuk memotong akar halus yang terdapat dalam tanah setelah mencapai kedalaman penuh. Kemudian corer secara perlahan ditarik dari dalam tanah sambil dilakukan pemutaran untuk mempertahankan agar sampel sedimen yang diambil tetap penuh dan lengkap. Langkah ketiga, sampel sedimen dibelah secara horizontal dan dibagi berdasarkan 5 kedalaman (5 sampel), yaitu $0-15 \mathrm{~cm}, 15-30 \mathrm{~cm}, 30-50 \mathrm{~cm}$, $50-100 \mathrm{~cm}$, dan $>100 \mathrm{~cm}$. Hanya bagian sub-sampel dari masing-masing kedalaman tersebut yang akan digunakan. Untuk kedalaman 0-15 cm yang diambil hanya pada kedalaman 5-10 $\mathrm{cm}$, kedalaman 15-30 cm pada kedalaman $20-25 \mathrm{~cm}$, kedalaman 30-50 cm pada kedalaman 35-40, kedalaman 50-100 $\mathrm{cm}$ pada kedalaman 70-80 dan kedalaman > 100. Langkah keempat, sub-sampel dimasukkan ke dalam zipper bag dan diberi label pada setiap kantong untuk memudahkan proses identifikasi dan analisis di laboratorium. Langkah terakhir, sampel selanjutnya dimasukkan kedalam cool box jika lokasi pengambilan data jauh dari laboratorium tempat analisis sampel.

\subsubsection{Pengambilan Data Mangrove}

Data mangrove diambil untuk keperluan identifikasi dengan cara identifikasi langsung pada masing-masing plot.

\subsubsection{Prosedur Analisis Sampel di Laboratorium}

Tahapan analisis di laboratorium adalah sebagai berikut sampel sedimen ditempatkan dalam cawan aluminium, kemudian dilakukan proses oven dengan suhu $60^{\circ} \mathrm{C}$ dan waktu selama 48 jam. Sampel yang telah kering dihaluskan dengan menggunakan mortar agar menjadi homogen sebelum proses pembakaran. Setiap sub-sampel yang sudah halus dimasukkan kedalam kantong plastik atau zipper bag. Langkah analisis terakhir, sebanyak \pm 2 gram sampel yang sudah dihaluskan kemudian ditimbang dan ditempatkan pada crucible porcelain. Selanjutnya dimasukkan ke dalam muffle furnace untuk dibakar dengan suhu $450{ }^{\circ} \mathrm{C}$ selama 4 jam dansampel kembali ditimbang.

\subsection{Metode Analisis Data}

Setelah dilakukan pembakaran semua sub-sampel sedimen, selanjutnya dilakukan penghitungan atau analisis data dengan menggunakan rumus yang tercantum dalam Buku Coastal Blue Carbon (Howard et al., 2014). Data yang dianalisis adalah kedalaman sampel, bulk density, dan persentase karbon organik pada sedimen. Dalam analisis data, persamaan yang digunakan sebagai berikut:

1. Bulk density tanah merupakan berat partikel per satuan volume tanah beserta porinya. Persamaan untuk menghitung bulk density, sebagai berikut:

Soil Bulk Density $=\underline{\text { Oven-dry mass }}$

$$
\text { Sample volume }
$$

Keterangan :

Soil bulk density = kepadatan $\operatorname{tanah}\left(\mathrm{g} / \mathrm{cm}^{3}\right)$

Oven-dry mass $=$ berat kering $(\mathrm{g})$

Sample volume $=$ volume tanah beserta porinya $\left(\mathrm{cm}^{3}\right)$

2. Densitas karbon (C) dihitung dengan menggunakan rumus berikut:

Soil C density = \%C XSoil Bulk Density

Keterangan :

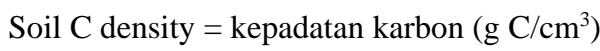

$\% \mathrm{C}=$ persentase kandungan karbon

3. Kandungan karbon pada tanah diestimasi dengan rumus berikut:

\section{Soil C $=$ Soil Bulk Density $\times$ Soil Depth Interval $\times$ \%C}

\section{Keterangan :}

Soil $\mathrm{C}=$ karbon organik tanah $(\mathrm{Mg} / \mathrm{ha})$

Soil Depth Interval = interval kedalaman sampel $(\mathrm{cm})$

Adapun proses secara umum penilaian stok karbon dapat ditampilkan dalam bagan (Gambar 2. Flowchart Penilai Stok Karbon). 


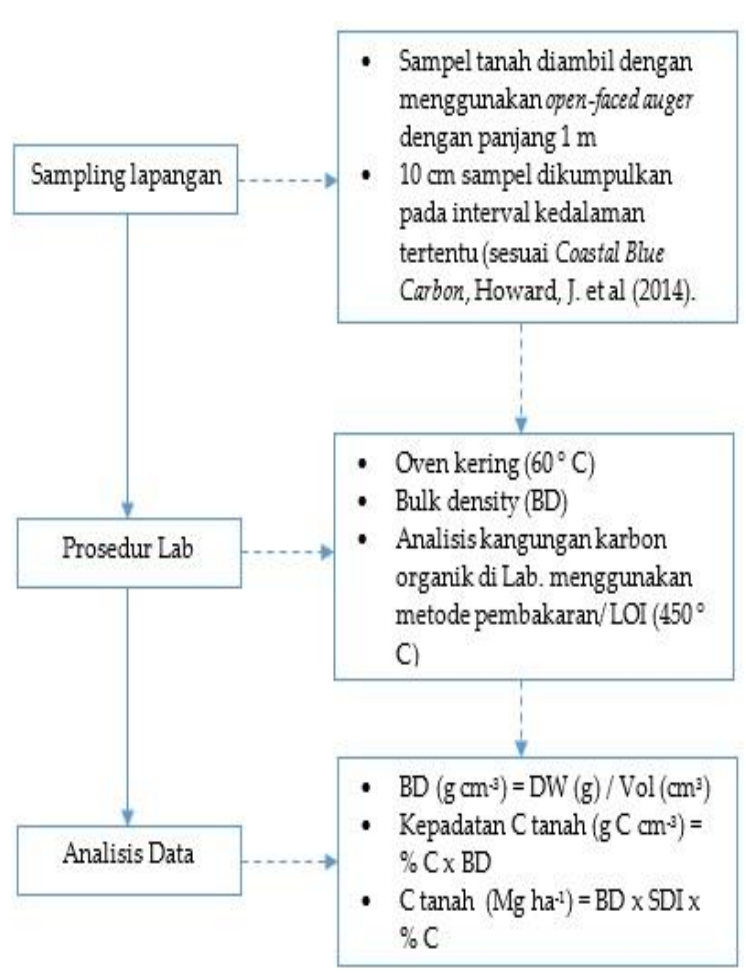

Gambar 2. Flowchart Penilaian Stok Karbon

\section{Hasil dan Pembahasan}

\subsection{Bulk density, \% Organic carbon, dan Soil C}

Data hasil perhitungan Bulk density, \% Organic carbon, dan Soil $C$ pada masing-masing kedalaman selama penelitian (Tabel 1. Data Penelitian). karbon pada tanah pada masing-masing plot pada 5 kedalaman (Tabel 1. Data Penelitian) didapat nilai rata-rata persentase F1 (Forest 1) sebesar 50,234 \%, F2 (Forest 2) sebesar 49,976\% dan F3 (Forest 3) sebesar 50.495\% dengan total Soil C pada F1 (Forest 1) sebesar 172.623 Mg/ha, F2 (Forest 2) sebesar176,531 $\mathrm{Mg} /$ ha dan F3 (Forest 3) sebesar 208.750 Mg/ha. Sehingga ratarata persentase karbon organik pada tanah di hutan mangrove alami Perancak sebesar 50,235\% atau 185,968 Mg/ha. Besarnya persentase karbon organik pada tanah hutan mangrove alami Perancak tidak berbeda jauh dengan hasil yang didapatkan pada penelitian Mahasani, dkk. (2015) di hutan mangrove bekas tambak Perancak sebesar 50,181\% atau $184.618 \mathrm{Mg} / \mathrm{ha}$. Besarnya simpanan $\mathrm{C}$ berkaitan dengan proses penyimpanan tanah C yang terlibat dalam sistem intertidal. Daun yang membusuk, ranting dan akar terkubur di tanah yang sering tertutup dengan air pasang surut. Lingkungan yang kurang oksigen ini menyebabkan dekomposisi bahan tumbuhan sangat lambat, sehingga menghasilkan penyimpanan karbon yang signifikan. Selain itu, Mahasani, $d k k$. (2015) menyatakan jumlah, jenis, dan kerapatan pohon dan faktor lingkungan diantaranya intensitas matahari, kadar air, suhu, dan kesuburan tanah yang memberikan perbedaan nilai simpanan karbon.

\subsection{Variasi vertikal persentase karbon organik pada tanah di hutan mangrove alami Perancak}

Secara vertikal terdapat variasi persentase karbon organik di lokasi penelitian berdasarkan kedalaman $(0-15 \mathrm{~cm} ; 15-30 \mathrm{~cm}$; 30$50 \mathrm{~cm} ; 50-100 \mathrm{~cm}$, dan> $100 \mathrm{~cm})$. Hasil analisis data didapat masing-masing nilai bulk density (Gambar 3. Variasi vertikal bulk density pada beberapa kedalaman tanah dari 3 plot di Mangrove Alami ) pada kedalaman $(0-15 \mathrm{~cm})$ pada plot 1 memiliki nilai terendah sebesar $0,07 \mathrm{~g} / \mathrm{cm} 3$ sedangkan nilai tertinggi pada kedalaman $(>100 \mathrm{~cm})$ pada plot 3 sebesar 0,20 $\mathrm{g} / \mathrm{cm} 3$. Kandungan bulk density tanah dipengaruhi oleh pasokan akar, serasah, dan dugaan kandungan karbon, pasokan bahan organik pada lapisan atas dan laju dekomposisi bahan organik dari akar rendah menyebabkan bulk density tanah pada lapisan

Tabel 1.Data Penelitian

\begin{tabular}{ccccc}
\hline Plot & $\begin{array}{c}\text { Kedalaman } \\
(\mathrm{cm})\end{array}$ & $\begin{array}{c}\text { Bulk density } \\
\left(\mathrm{g} \mathrm{cm}^{-3}\right)\end{array}$ & $\begin{array}{c}\text { \% Organic } \\
\text { Carbon }\end{array}$ & $\begin{array}{c}\text { Soil C } \\
\left(\mathrm{Mg} \mathrm{ha}^{-1}\right)\end{array}$ \\
\hline \multirow{4}{*}{ I } & $0-15$ & 0.07 & 48.762 & 17.361 \\
& $15-30$ & 0.12 & 50.754 & 31.194 \\
& $30-50$ & 0.14 & 50.977 & 36.265 \\
& $50-100$ & 0.12 & 51.821 & 62.962 \\
& $>100$ & 0.10 & 48.854 & 24.842 \\
\hline \multirow{4}{*}{ II } & $0-15$ & 0.08 & 49.408 & 20.394 \\
& $15-30$ & 0.13 & 50.968 & 34.292 \\
& $30-50$ & 0.11 & 50.363 & 28.697 \\
& $50-100$ & 0.12 & 51.244 & 60.708 \\
III & $>100$ & 0.14 & 47.899 & 32.439 \\
& $0-15$ & 0.14 & 50.257 & 34.242 \\
& $15-30$ & 0.14 & 50.911 & 34.663 \\
& $30-50$ & 0.13 & 50.805 & 34.125 \\
& $50-100$ & 0.11 & 51.661 & 57.434 \\
\end{tabular}

\subsection{Estimasi persentase karbon organik pada tanah di hutan mangrove alami Perancak}

Pada masing-masing lokasi penelitian dilakukan pengamatan vegetasi mangrove dan ditemukan 4 jenis mangrove yaitu Rhizophora apiculata, Avicennia marina, Xylocarpus granatum, dan Sonneratia alba. Berdasarkan hasil analisis kandungan tanah yang lebih bawah tidak jauh berbeda (Siringoringo, 2013). Kresnabayu (2017) juga menyatakan padatan tanah, pori-pori tanah, struktur, tekstur dan ketersediaan bahan organik serta pengolahan tanah akan mempengaruhi perbedaan nilai bulk density. 


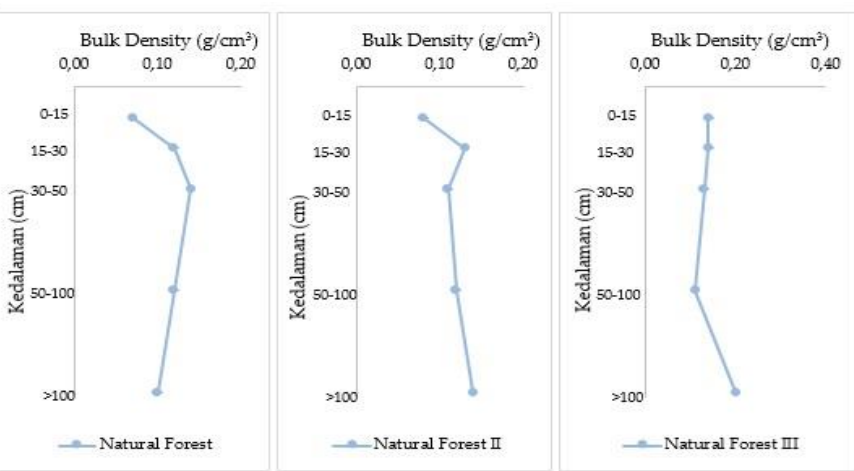

Gambar 3. Variasi vertikal bulk density pada beberapa kedalaman tanah dari 3 plot di Mangrove Alami

Nilai \% karbon tanah (Gambar 4. Variasi vertikal \%C pada beberapa kedalaman tanah, dari 3 plot di Mangrove Alami) terendah pada kedalaman (>100 $\mathrm{cm}$ ) pada plot 2 sebesar $47,899 \%$ sedangkan nilai tertinggi pada kedalaman $(50-100 \mathrm{~cm})$ pada plot 1 sebesar $51,821 \%$. Nilai persentase karbon sangat berhubungan dengan kandungan karbon organik yang akan mempengaruhi simpanan karbon. Mahasani, dkk. (2016) menyatakan nilai kandungan karbon organik besar, maka kandungan organik yang tersimpanan juga besar dan sebaliknya.
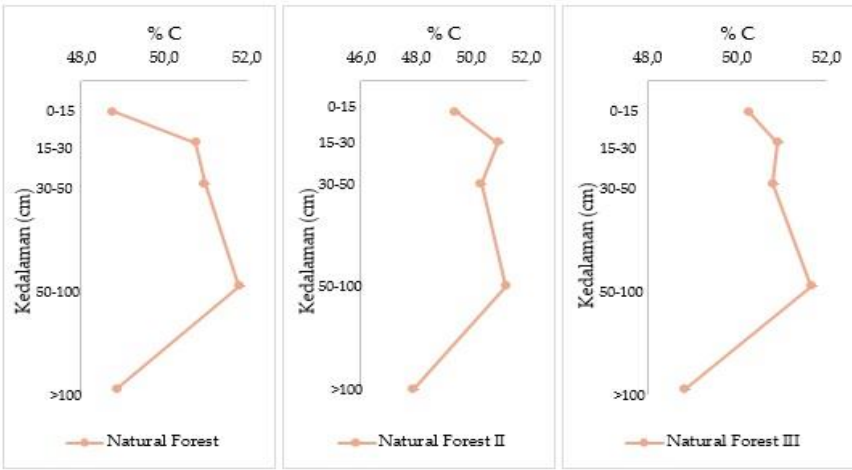

Gambar 4. Variasi vertikal \%C pada beberapa kedalaman tanah dari 3 plot di Mangrove Alami

Nilai simpanan karbon (Gambar 5. Variasi vertikal soil $C$ pada beberapa kedalaman tanah dari 3 plot di Mangrove Alami) terendah pada kedalaman $(0-15 \mathrm{~cm})$ sebesar $17,361 \mathrm{Mg} / \mathrm{ha}$ sedangkan nilai tertinggi pada kedalaman $(50-100 \mathrm{~cm})$ sebesar $62,962 \mathrm{Mg} / \mathrm{ha}$. Menurut Mahasani (2016) terdapat berbagai faktor yang mempengaruhi simpanan karbon dalam tanah, diantaranya faktor lingkungan seperti pemanfaatan lahan dan faktor fisika-kimia tanah seperti suhu, $\mathrm{pH}$, pori-pori, tekstur, bulk density, dsb). Variasi vertikal tersebut diduga dipengaruhi oleh tipe geomorfik, ketersediaan nutrien, serta hidrologi.

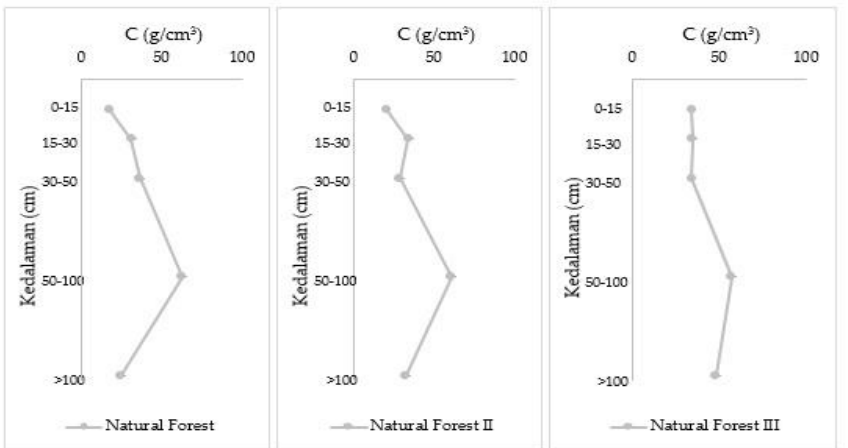

Gambar 5. Variasi vertikal soil $C$ pada beberapa kedalaman tanah dari 3 plot di Mangrove Alami

\section{Simpulan}

Persentase karbon organik pada tanah di hutan mangrove alami Perancak sebesar 50,235\% atau 185,968 Mg/ha. Dari ketiga plot didapatkan hasil bahwa secara vertikal persentase karbon organik pada tanah di hutan mangrove alami Perancak bervariasi. Nilai bulk density terendah pada kedalaman $(0-15 \mathrm{~cm})$ sebesar 0,07 $\mathrm{g} / \mathrm{cm} 3$ pada plot 1 dan tertinggi pada kedalaman $(>100 \mathrm{~cm})$ sebesar 0,20 g/cm3 pada plot 3; nilai \% karbon organik terendah pada kedalaman $(>100 \mathrm{~cm})$ sebesar $47,899 \%$ pada plot 2 dan tertinggi pada kedalaman $(50-100 \mathrm{~cm})$ sebesar $51,821 \%$ pada plot 1; nilai soil $C$ terendah pada kedalaman $(0-15 \mathrm{~cm})$ sebesar $17,361 \mathrm{Mg} / \mathrm{ha}$ dan tertinggi pada kedalaman $(50-100 \mathrm{~cm})$ sebesar $62,962 \mathrm{Mg} / \mathrm{ha}$ pada plot 1 .

\section{Ucapan terimakasih}

Penulis mengucapkan terima kasih kepada reviewer Ibu Dra. Ni Luh Watiniasih, M.Sc., Ph.D dan Bapak I Nyoman Giri Putra, S.Pd., M.Si atas saran dan masukan dalam pembuatan jurnal ilmiah ini. Terima kasih juga penulis ucapkan kepada pembimbing lapangan Nuryani Widagti, M.Si atas arahan dan bimbingan serta bantuan yang telah diberikan selama pengambilan data di Balai Penelitian dan Observasi Laut (BPOL).

\section{Daftar Pustaka}

Ati, R. N. A., Rustam, A., Kepel, T. L., Sudirman, N., Astrid, M., Daulat, A., Mangindaan, P., Salim, H. L., Hutahean, A. A., 2014. Stok Karbon dan Stuktur Komunitas Mangrove sebagai Blue Carbon di Tanjung Lesung, Banten. Jurnal Segara. 10(2). 119-127

Balai Riset dan Observasi Kelautan, 2009. Riset Observasi dan Kajian Pemanfaatan Kawasan Konservasi Laut di Estuari Perancak. Bali : Balai Riset dan Observasi Kelautan - DKP

Duarte, C. M., Middelburg, J. J., Caraco, N., 2005. Major Role of Marine Vegetation on The Oceanic Carbon Cycle. Biogeosciences. 2. 1-8. Doi: https://doi.org/10.5194/bg-2-1-2005

Donato et al., 2012. Mangrove adalah salah satu hutan terkaya karbon di kawasan tropis. Brief CIFOR. 12. Doi: 10.17528/cifor/003773

Howard, J., Hoyt, S., Isensee, K., Telszewski, M., Pidgeon, E., 2014. Coastal Blue Carbon: Methods for Assessing Carbon Srocks and Emission Factors in Mangroves, Tidal Salt Marshes, and Seagrass Meadows. Virginia, USA: Conservation Internasional, Intergovernmental Oceanographic Commission of UNESCO, Internasional Union for Conservastion of Nature

Jobbagy, E. G., Jackson, R. B., 2000. The Vertical Distribution of Soil Organic Carbon and Its Relation to Climate and Vegetation. Ecological Applications. 10(2). 423-436. Doi: https://doi.org/10.1890/10510761(2000)010[0423:TVDOSO]2.0.CO;2

Kresnabayu, I. M. P., 2017. Pengaruh Kerapatan Hutan Mangrove Berbasis Data Penginderaan Jauh Terhadap Karbon Organik Tanah Di Estuari Perancak. Kabupaten Jembrana-Bali. Skripsi. Bukit Jimbaran, Indonesia: Program Studi Ilmu Kelautan, Fakultas Kelautan dan Perikanan Universitas Udayana

Mahasani, I. G. A. I., Widagti, N., Karang, I. W. G. A., 2015. Estimasi Persentase Karbon Organik di Hutan Mangrove Bekas Tambak, Perancak, Jembrana, Bali. Journal of Marine and Aquatic Sciences. 1. 1418. Doi: https://doi.org/10.24843/jmas.2015.v1.i01.14-18

Mahasani, I.G.A.I. (2016). Karbon Organik Di Bawah Permukaan Tanah Pada Kawasan Rehabilitasi Hutan Mangrove, Taman Hutan Raya Ngurah Rai, Bali. Prosiding Seminar Nasional Kelautan. Universitas Trunojoyo Madura. 27 Juli 2016

Mcleod, E., Chmura, G. L., Bouillon, S., Salm, R., Björk, M., Duarte, C. M., 2011. A blueprint for blue carbon: toward an improved understanding of the role of vegetated coastal habitats in sequestering $\mathrm{CO} 2$. Frontiers in Ecology and the Environment. 9. 552-560. Doi: https://doi.org/10.1890/110004 